\title{
Drug reaction with eosinophilia and systemic symptom induced by carbamazepine: a case report
}

\author{
Rahul R. Damor*, Amita R. Kubavat, Kiran G. Piparva
}

Department of Pharmacology, PDU Government Medical College, Rajkot, Gujrat, India

Received: 22 February 2019

Revised: 19 March 2019

Accepted: 28 March 2019

*Correspondence to:

Dr. Rahul R. Damor,

Email:

drrahuldamor@gmail.com

Copyright: (C) the author(s), publisher and licensee Medip Academy. This is an openaccess article distributed under the terms of the Creative Commons Attribution NonCommercial License, which permits unrestricted noncommercial use, distribution, and reproduction in any medium, provided the original work is properly cited.

\begin{abstract}
Drug reaction with eosinophilia and systemic symptoms (DRESS) syndrome is a severe, potentially life-threatening acute adverse drug reaction (ADR), typically characterized by a long latency period (2-6 weeks to 3 months) from drug exposure. DRESS syndrome is defined by the presence of fever, cutaneous eruption, lymphadenopathy, systemic or asymptomatic internal organ involvement (e.g. Hepatitis, carditis, interstitial nephritis, interstitial pneumonitis, etc.) and haematological abnormalities, mainly leucocytosis, eosinophilia and sometimes atypical lymphocytosis. There are around 50 culprit drugs which cause DRESS syndrome e.g. carbamazepine, phenytoin, allopurinol, sulfa derivatives, antidepressants, antiepileptics, non-steroidal anti-inflammatory drugs and antimicrobials. The incidence of DRESS syndrome has been estimated to be between 1 in 1,000 and 1 in 10,000 drug exposures. There are many reported cases of DRESS syndrome due to carbamazepine, phenytoin, vancomycin, levitiracitam, ceftriaxone etc. Author presented a case of DRESS syndrome by carbamazepin. RegiSCAR and Japanese consensus group have developed specific criteria for making the diagnosis of DRESS syndrome. The patient described here met the majority of criteria according to RegiSCAR scoring guidelines for a diagnosis of DRESS syndrome induced by carbamazepine. As per RegiSCAR diagnostic criteria author had concluded that this was a "Definite" case of DRESS (Drug Reaction with Eosinophilia and Systemic Symptom) syndrome induced by carbamazepine. Carbamazepine is most common broadspectrum antiepileptic drugs so, this case report will raises awareness among physician to suspect DRESS syndrome in patients who present unusual complaints and skin findings after starting antiepileptic drugs.
\end{abstract}

Keywords: Carbamazepine, DRESS, RegiSCAR

\section{INTRODUCTION}

Drug reaction with eosinophilia and systemic symptoms (DRESS) syndrome is a severe, potentially life-threatening acute adverse drug reaction (ADR), typically characterized by a long latency period (2-6 weeks to 3 months) from drug exposure. ${ }^{1}$ DRESS syndrome is defined by the presence of fever, cutaneous eruption, lymphadenopathy, systemic or asymptomatic internal organ involvement (e.g. hepatitis, carditis, interstitial nephritis, interstitial pneumonitis, etc.) and haematological abnormalities, mainly leucocytosis, eosinophilia and sometimes atypical lymphocytosis. There are around 50 culprit drugs which cause DRESS e.g. carbamazepine, phenytoin, allopurinol, sulfa derivatives, and antidepressants, antiepileptics, non-steroidal antiinflammatory drugs and antimicrobials. The incidence of DRESS has been estimated to be between 1 in 1,000 and 1 in 10,000 drug exposures. ${ }^{2}$ There are many reported cases of DRESS due to carbamazepine, phenytoin, vancomycin, levitiracitam, ceftriaxone etc. ${ }^{3,4}$ So here, author presented a case of DRESS syndrome by carbamazepine. 


\section{CASE REPORT}

A 40-year old female was admitted to dermatology ward of hospital with a chief complains of redness with itching started from abdominal region and gradually spread over most of the body surface within 2 days. History of fever before development of skin lesion. The skin rash was accompanied with breathlessness.
On physical examination, facial and pedal non pitting edema, bilateral cervical lymphadenopathy and pallor conjunctiva was observed. On cutaneous examination, there was multiple bilateral symmetrical dusky erythematous papules with exfoliation was observed on all over face, trunk, back and upper limbs. Negative history of atopy, drug reactions, other skin disease and any major illness were found.

Table 1: RegiSCAR of the patient. ${ }^{1,5,6}$

\begin{tabular}{|c|c|c|c|c|}
\hline \multirow[b]{2}{*}{ Criteria } & \multicolumn{3}{|c|}{ Score } & \multirow[b]{2}{*}{ Case score } \\
\hline & No & Yes & Unknown & \\
\hline Fever $\geq 38.5$ & & 1 & & 1 \\
\hline Enlarged lymph nodes ( $\geq 2$ sites, $>1 \mathrm{~cm}$ ) & & 1 & & 1 \\
\hline $\begin{array}{l}\text { Peripheral eosinophilia } \\
0.7-1.5 \times 10^{9} / \mathrm{L} \text { or } 10-19.9 \% \\
\geq 1.5 \times 10^{9} / \mathrm{L} \text { or } \geq 20 \%\end{array}$ & -1 & & & -1 \\
\hline Atypical lymphocytes & & & -1 & -1 \\
\hline \multicolumn{5}{|l|}{ Skin involvement } \\
\hline Extent of cutaneous eruption $>50 \%$ & & 1 & & 1 \\
\hline Skin Rash suggesting DRESS & & 1 & & 1 \\
\hline Biopsy suggesting DRESS & & 1 & & 1 \\
\hline \multicolumn{5}{|l|}{ Organ involvement } \\
\hline One & & 1 & & 1 \\
\hline 2 or more & & 1 & & 1 \\
\hline Resolution $\geq 15$ days & & 1 & & 1 \\
\hline $\begin{array}{l}\text { Laboratory results negative for at least } 3 \text { of following: } \\
\text { - } \quad \text { ANA } \\
\text { - } \quad \text { Blood culture } \\
\text { - } \quad \text { ChAlamy } / \mathrm{HBV} / \mathrm{HCV} \text { serology } \\
\end{array}$ & & 1 & & 1 \\
\hline Total score $<2$ no case; $2-3$ possible case; $>5$ definite case & -1 & 9 & -1 & 7 \\
\hline
\end{tabular}

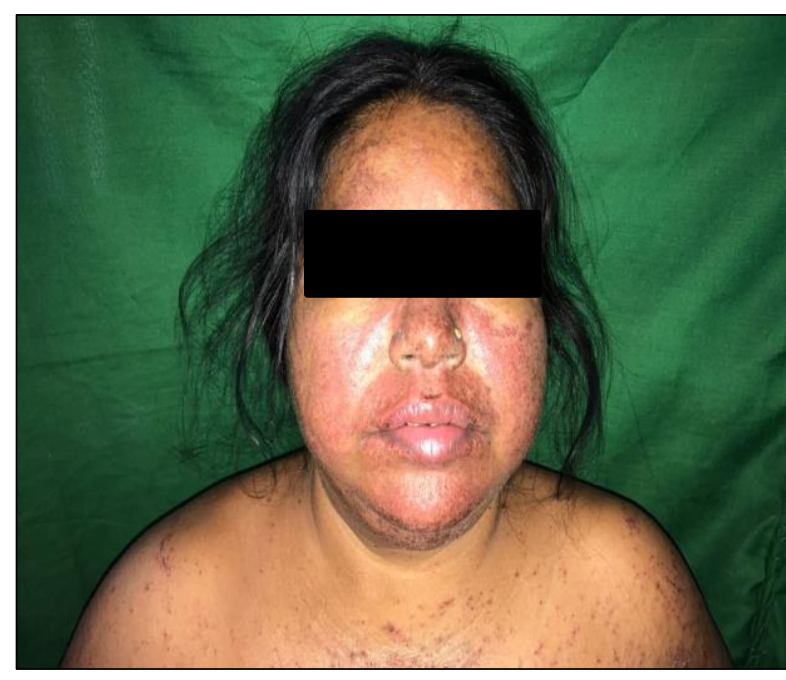

Figure 1: Skin rash and facial oedema region.

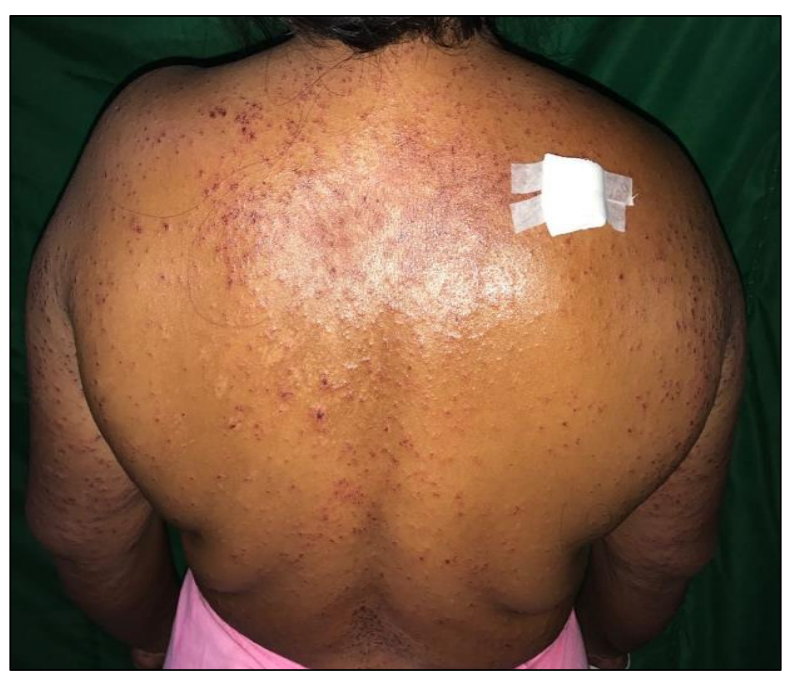

Figure 2: Skin rash involving back. 
Total count and differential count, platelet count, RBS, S. creatinine, S. protein, S. electrolyte and serology profile were within normal limit. While high erythrocyte sedimentation rate (ESR), low level of $\mathrm{Hb}$, slight rise in serum bilirubin was observed on investigation profile. Test for serum HIV was reactive and RPR and HEV were negative, sputum test was negative.

Chest X-ray shows borderline cardiomegaly. Mild splenomegaly and mild hepatomegaly with few bilateral enlarged lymph nodes with fatty hilum were observed in ultra-sonography of abdomen.

The skin biopsy showed epidermal orthokeratosis and basal cell vacuolization with apoptotic keratinocytes. There were also inflammatory cells seen in perivascular area of dermis. The patient had history of breathlessness before 1 month. Patients was on carbamazepine and amitriptyline for post herpetic neuralgia since 15 days.

From patient's presentation and history, dermatologist diagnosed this was a case of DRESS syndrome as per diagnostic criteria developed by international study group investigation severe cutaneous reaction (SCAR).

Patients was managed symptomatically with corticosteroid, antibiotic, antihistaminic and analgesic drugs by parenteral, oral route as well topical preparation. Patient was resolved and discharged after 14 days (Another diagnostic criteria established by a Japanese consensus group also match with the patient presentation).

\section{DISCUSSION}

The term "drug rash with eosinophilia and systemic symptoms" (DRESS) was first introduced in 1996 by Bocquet, patients exhibiting a drug-induced condition characterized by an extensive rash, fever, lymphadenopathy. This may include hematologic abnormalities, hepatitis and involvement of the organs like kidneys, lungs, heart or pancreas. Patients with DRESS usually presents within 8 week of medicine consumption approximately. Aromatic anticonvulsants (phenytoin, phenobarbital and carbamazepine) are the most common cause of DRESS. ${ }^{5}$

The exact pathogenesis of DRESS syndrome is not known. However, three components are essential for DRESS syndrome, a genetic component that alters immune response, a triggering factor (mostly a viral infection) and defect in drug metabolism resulting in failure to eliminate drug intermediates. ${ }^{5,7}$

Aromatic anticonvulsants such as carbamazepine, phenytoin and phenobarbital are metabolized by the hepatic cytochrome CYP450 enzymes and converted into toxic arene oxides that are normally enzymatically converted to non-toxic metabolites by epoxide hydroxylase or glutathione transferase. In cases of defective or deficient epoxide hydroxylase, arene oxides can accumulate and cause direct cellular toxicity or immune response. ${ }^{1,8}$

Recent studies have suggested a close relationship between herpes viruses and DRESS syndrome. Although HHV 6 was the initial virus proposed as a causative agent in DRESS syndrome, recent studies have shown a sequential involvement of many herpes viruses extended over a period of time. The cascade of viral reactivation is initiated by EBV or HHV-6 and extends over a period, followed by HHV-7 reactivation and eventually CMV proliferation. In support of this hypothesis, herpes virus genome can be detected at high frequency with the clinical symptoms., ${ }^{4,9}$

RegiSCAR and Japanese consensus group have developed specific criteria for making the diagnosis of DRESS. ${ }^{3}$ To meet the definition of DRESS, patients must have five of total eight RegiSCAR score- an acute rash, fever above $38^{\circ} \mathrm{C}$, lymphadenopathy at two sites, involvement of at least one internal organ, and abnormalities in lymphocyte and eosinophil counts, Resolution $\geq 15$ days and laboratory results negative for at least three serology tests.

Concerning Japanese consensus group the diagnosis requires meeting seven of the nine criteria in this system or all of the first five- a maculopapular rash developing $>3$ weeks after drug initiation, clinical symptoms continuing $>2$ weeks after stopping therapy, fever $>38^{\circ} \mathrm{C}$, liver abnormalities (ALT $>100$ IU/L) or other organ involvement, leukocytosis, atypical lymphocytes, eosinophilia, lymphadenopathy or HHV-6 reactivation.

The patient described here met the majority of criteria according to RegiSCAR scoring guidelines for a diagnosis of DRESS induced by carbamazepine. As per clinical, laboratory profile and history of recent carbamazepine ingestion dermatologist confirmed that this was a case of DRESS induced by carbamazepine. The patient didn't have eosinophilia but other haematological conditions like decrease in haemoglobin level and rise in erythrocyte sedimentation rate found.

There is a $10 \%$ mortality rate from DRESS, mostly due to liver damage thought to be secondary to eosinophilic infiltration. The most important steps in managing patients with DRESS are recognizing the presence of this syndrome and immediately stopping the offending drug. Systemic corticosteroids have been considered the treatment of choice, especially in patients with internal organ involvement.

The French Society of Dermatology published a report in 2010 outlining a consensus on therapeutic management of DRESS. They recommend the use of systemic corticosteroids at a dose equivalent to $1 \mathrm{mg} / \mathrm{kg} / \mathrm{day}$ of prednisone in patients with any sign of severity including transaminases greater than five times normal, renal involvement, pneumonia, hemophagocytosis or cardiac involvement. $^{3}$ 


\section{CONCLUSION}

This was a "Definite" case of DRESS (Drug Reaction with Eosinophilia and Systemic Symptom) syndrome induced by carbamazepine. Carbamazepine is most common broadspectrum antiepileptic drugs so, this case report will raises awareness among physician to suspect dress syndrome in patients who present unusual complaints and skin findings after starting antiepileptic drugs.

Funding: No funding sources Conflict of interest: None declared

Ethical approval: Not Required

\section{REFERENCES}

1. Gancheva T, Gancheva D, Troeva Z, Velev V, Hristakieva E, Tsokeva Z, et al. Carbamazepineinduced DRESS syndrome: a case report. J Pharmacol. 2017;5(1):1063.

2. Ting TY. Anticonvulsant hypersensitivity syndrome: identification and management. Current Treatment Options Neurol. 2007;9(4):243-8.

3. Omairi NE, Abourazzak S, Chaouki S, Atmani S, Hida M. Drug reaction with eosinophilia and systemic symptom (DRESS) induced by carbamazepine: a case report and literature review. Pan Afr Med J. 2014;18:9.

4. Vlachopanos G, Kokkona A, Zerva A, Stavroulaki E, Zacharogiannis C, Agrafiotis A. Atypical DRESS syndrome induced by lenalidomide in chronic hemodialysis. J Clin Exp Pathol. 2016;6(3):1-3.
5. Waseem D, Latief M, Sofi N, Dar I, Khan Q. DRESS syndrome: a review and update. Skin Dis Skin Care. 2016;1:1.

6. Kardaun SH, Sidoroff A, Valeyrie-Allanore L, Halevy S, Davidovici BB, Mockenhaupt M, et al. Variability in the clinical pattern of cutaneous side-effects of drugs with systemic symptoms: does a DRESS syndrome really exist?. Brit J Dermatol. 2007;156(3):609-11.

7. Bocquet $\mathrm{H}$, Bagot $\mathrm{M}$, Roujeau JC. Drug-induced pseudolymphoma and drug hypersensitivity syndrome (drug rash with eosinophilia and systemic symptoms: DRESS). Seminars Cutaneous Med Surg. 1996;15(4):250-257.

8. Shear NH, Spielberg SP. Anticonvulsant hypersensitivity syndrome. In vitro assessment of risk. J Clin Investigation. 1988;82(6):1826-32.

9. Fiszenson-Albala F, Auzerie V, Mahe E, Farinotti R, Durand-Stocco C, Crickx B, et al. A 6-month prospective survey of cutaneous drug reactions in a hospital setting. Brit J Dermatol. 2003;149(5):101822.

Cite this article as: Damor RR, Kubavat AR, Piparva KG. Drug reaction with eosinophilia and systemic symptom induced by carbamazepine: a case report. Int J Basic Clin Pharmacol 2019;8:1115-8. 